extent, dual education systems enable young people to acquire not simply technical skills, but broadly defined competencies that serve as the foundation for rewarding careers and social esteem. However, actual implementation of dual education outside the core Germanic countries in Europe has proven to be extremely challenging. However, in some countries, local partnerships embracing elements of dual education have formed, uniting educational institutions, government entities, and firms in partnerships to upgrade VET. This paper discusses some of the characteristic patterns of such partnerships and the pathways leading to their formation. The paper focuses particularly on the US case.

Keywords: vocational education and training (VET), dual education, public-private partnerships, USA. JEL Classification: I28, I25, J24.

\title{
По Янг
}

Китайский институт исследований финансирования образования, Пекинский университет, Китай

\section{Координация государственно-частного партнерства в сфере среднего профессионального образования: опыт Китая ${ }^{1}$}

Аннотация. Китайское правительство поддерживает развитие государственно-частных партнерств (ГЧП) в сфере среднего профессионального образования (СПО) для решения проблемы коллективных действий на рынке подготовки квалифицированных кадров. В статье анализируются базовые принципы реформы ГЧП в области профессионально-технического обучения и ее текущее состояние. Описательный анализ, основанный на 257 парах «фирма-учреждение СПО» и 1679 конкретных случаях партнерств между 171 образовательным учреждением и 257 производственными предприятиями, показывает наиболее распространенные формы сотрудничества на уровне провинций, в том числе предоставление фирмами мастеров-наставников, обучение преподавателей, стипендии и заработные платы и финансовую помощь учащимся. Среди фирм наблюдается значительная степень вариации в популярности того или иного типа сотрудничества. Выбор фирмой модели ГЧП зависит от формы собственности компании. На основе анализа множества кейс-стади в различных китайских регионах статья показывает, как посреднические организации способствуют сотрудничеству между фирмами, а также между образовательными учреждениями и фирмами в рамках трех моделей координации ГЧП: модели под руководством фирм, модели под руководством органов власти и модели совместной координации. В заключении представлены основные выводы и некоторые идеи для будущей координации внутри ГЧП.

Ключевые слова: государственно-истное партнерство, Китай, посреднические организачии.

Классификация JEL: D22, I28, I25, J24.

\section{Введение}

Несмотря на быстрый рост сектора среднего профессионального образования (СПО) с конца 1990-х годов, обеспечение экономики работниками с нужными навыками по-прежнему остается в Китае нерешенной задачей. Отчеты IBM говорят о существенном несоответствии навыков требованиям промышленности (IBM, 2016, 2017). В 2015 г. только $19 \%$ работников относились к числу квалифицированных, а доля высококвалифицированных работников составляла менее $5 \%$.

Треть рабочих в промышленности была представлена мигрантами, из которых почти три четверти не закончили даже девяти классов (National Statistics Bureau, 2016).

Истоки несоответствия квалификаций и нехватки навыков имеют глубокие институциональные корни. Однако ключевая проблема - провал рынка в части организации коллективных действий. С одной стороны, сотрудничество между фирмами в сфере обучения работников затруднено из-за потенциаль-

\footnotetext{
${ }^{1}$ По Янг благодарит за финансовую поддержку Фонд социальных наук Китая (China Social Science Foundation).
} 
ной угрозы переманивания кадров (Acemoglu, Pischke, 1998). Вследствие этого фирмы неохотно инвестируют в обучение и предпочитают привлекать работников непосредственно с рынка труда. С другой стороны, сотрудничество между учреждениями СПО и фирмами также труднодостижимо. Расширение работы с компаниями означает для учебных заведений высокие издержки и неопределенные выгоды: они должны согласовывать учебную программу с потребностями отрасли, гарантировать соответствие отраслевым стандартам, создавать новые учебные центры и лаборатории. Сотрудничество также подразумевает высокие издержки и для фирм.

Чтобы решить эти проблемы, регионы КНР в кооперации с государственными и частными партнерами разработали ряд инновационных решений для стыковки спроса и предложения на рынке СПО. Анализ нескольких успешных кейсов партнерства в области обучения сотрудников позволяет увидеть важную роль посреднических организаций, которые способствуют сотрудничеству между фирмами, учреждениями СПО и органами власти. Однако мало известно о том, как организованы такие партнерства и кто осуществляет их координацию. Данная статья рассматривает существующие в Китае модели государственночастного партнерства (ГЧП) в СПО, используя уникальную базу данных о ГЧП между фирмами и учреждениями СПО и материалы глубинных интервью, проведенных в 2016-2017 гг. в четырех городах в трех провинциях КНР.

\section{1. Институциональный контекст}

\section{1. Трансформация системы}

подготовки квалифицированных кадров

Следуя модели Советского Союза, правительство КНР в 1950-е годы создало систему СПО под строгим государственным контролем, напрямую привязывая подготовку новых работников к запросам государственных предприятий (Wang, 2014; Yang, Wang, 2017). Государство обязало государственные профессиональные училища проводить теоретическую подготовку будущих рабочих, а государственные предприятия - обучать их практическим навыкам.
Рыночные реформы в начале 1980-х годов привели к дерегулированию рынка труда и лишению государственных предприятий образовательных функций. Большинство профессионально-технических училищ, связанных с государственными предприятиями и отраслевыми министерствами, были переданы в ведение Министерства образования. Система СПО Китая стала более похожей на модель подготовки кадров в странах Северной Европы, где государство оказывало полную поддержку обучению студентов в учреждениях СПО, а участие фирм в этом процессе было маргинальным (Busemeyer, Trampusch, 2012). В результате, однако, навыки и квалификация выпускников СПО стали меньше соответствовать потребностям предприятий.

Чтобы решить эту проблему, правительство КНР начало внедрять модель государственно-частного партнерства в сфере СПО. Теоретически ГЧП может решить проблему коллективных действий путем создания стимулов для предприятий. Совместные инвестиции фирм, учреждений СПО и органов власти могут гарантировать, что действия каждого партнера соответствуют его обязательствам. Формат ГЧП также предусматривает, что фирмы, учебные заведения и органы власти подписывают юридически обязывающие договора, которые создают институциональную базу для их сотрудничества.

Основываясь на анализе ряда кейсов, мы полагаем, однако, что проблему коллективных действий на рынке СПО в Китае решает не государственно-частное партнерство само по себе, а, скорее, заложенные в программы ГЧП посреднические организации, которые содействует сотрудничеству между фирмами, а также между фирмами и учебными заведениями в системе профессионального образования. Мы подробно рассмотрим роль и функцию посредников в разд. 3.

\section{2. Общие рамки развития ГЧП в сфере СПО}

Правительство КНР в течение ряда лет поощряло государственно-частное партнерство в сфере СПО, уделяя особое внима- 
ние стимулированию сотрудничества между учреждениями СПО и предприятиями. На национальном уровне за развитие участия фирм в процессе обучения на базе учреждений СПО отвечали Государственный совет и Министерство образования. Они обеспечили изменение законодательства и общие благоприятные условия для создания партнерств ${ }^{2}$. На региональном уровне в некоторых провинциях было разработано местное регулирование, определяющее условия, содержание и типы партнерств, а также меры поощрения и взыскания для участников ГЧП в сфере СПО.

Министерство финансов и Комитет по развитию и реформам в последнее время пытаются внедрять новые формы ГЧП с привлечением социальных партнеров, к которым относятся как традиционные производственные предприятия, так и коммерческие специализированные учебные заведения и управляющие компании. Однако в рамках этих новых ГЧП подготовка кадров ведется не для социальных партнеров, а для других работодателей. Следовательно, на их примере сложно понять, как решаются проблемы координации внутри ГЧП. Поэтому в данной работе мы в первую очередь рассматриваем партнерства между государственными учреждениями СПО и производственными предприятиями, которые занимаются подготовкой кадров непосредственно для нужд партнеров.

Чтобы определить характеристики и распространенность таких партнерств на национальном уровне, мы создали базу данных о ГЧП, в основе которой лежат годовые отчеты предприятий об их участии в процессе СПО в 2016 г. Отчеты были предоставлены добровольно и размещены в Интернете Министерством образования. Мы осуществили кодирование данных отчетов, используя 10 категорий партнерств фирм с учреждениями СПО. К этим категориям были отнесены:

1) разработка учебных планов;
2) оценка успеваемости и проведение выпускных экзаменов;

3) финансовая помощь учащимся;

4) стипендии и зарплаты;

5) предоставление оборудования;

6) инвестиции;

7) обучение преподавателей;

8) предоставление мастеров-наставников;

9) гарантии занятости для выпускников;

10) совместный подбор кадров.

Эти категории схожи с типологией, описанной И. Маркесом ${ }^{3}$, и их также можно классифицировать по масштабу и глубине кооперации ${ }^{4}$. Затем мы соотнесли эти партнерства с характеристиками фирм и учебных заведений и информацией о провинциях.

Отчеты содержат информацию о 257 парах «фирма-учреждение СПО» и 1679 конкретных случаях партнерств между 171 учреждением СПО (а это - 13\% всех технических училищ в КНР) и 257 производственными предприятиями. Это означает, что на каждую пару «фирма-учреждение СПО» приходится около десяти партнерских практик, а каждая фирма участвует в 6,5 подобных механизмах сотрудничества. На рис. 1 видно, что в 26 из 31 китайских провинций фирмы инвестировали в четыре наиболее распространенных типа сотрудничества, а именно: в предоставление фирмами мастеров-наставников, подготовку преподавателей, стипендии и заработные платы студентам и финансовую помощь студентам. Наименее распространены такие типы сотрудничества, как совместный подбор кадров, инвестиции и передача оборудования, участие фирм в оценке обучающихся, но тем не менее они встречаются 23 провинциях.

На рис. 2 показано распространение десяти категорий ГЧП на 257 фирмах и суммируется число фирм, участвующих в каждом типе ГЧП. Из графика видно, что существует большая степень вариации в популярности каждого из типов партнерств среди фирм. Наиболее

\footnotetext{
2 Данные меры включали планы углубления сотрудничества между образовательными учреждениями и фирмамипартнерами, создание новых форм учреждений СПО со смешанной структурой собственности и т.д.

${ }^{3}$ См. статью в данном номере.

${ }^{4}$ См. статью Т. Ремингтона в данном номере.
} 


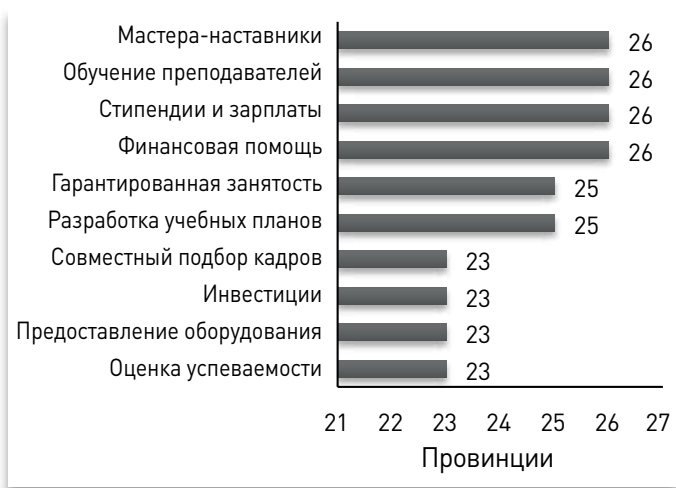

Рис. 1

Региональное распределение форм ГЧП

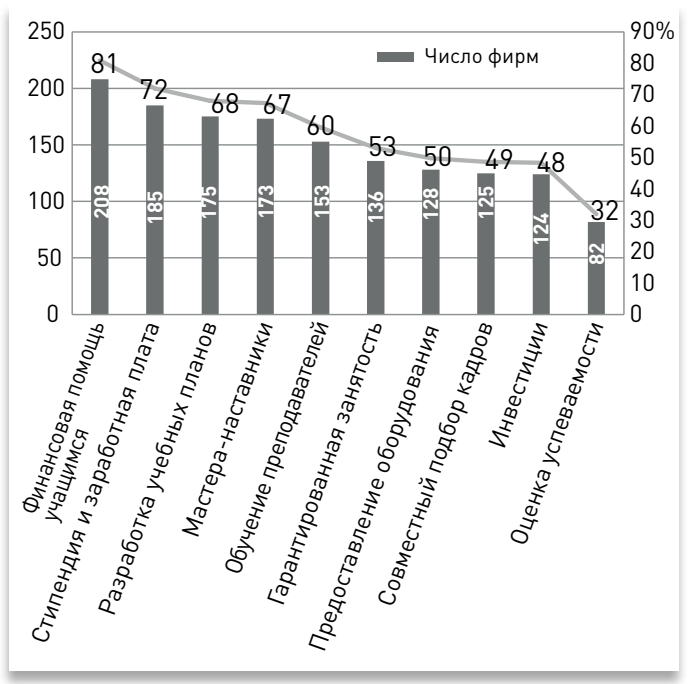

Рис. 2

Распространенность 10 форм (категорий) ГЧП среди предприятий

распространенными формами ГЧП являются финансовая помощь студентам, назначение фирмами мастеров-наставников, участие фирм в разработке учебных планов и предоставление стипендий и заработных плат студентам. Более двух третей фирм вовлечены в такие ГЧП, и только $32 \%$ фирм участвуют в оценке успеваемости студентов.

Когда фирмы-партнеры принимают решение о сотрудничестве с учреждениями СПО для обеспечения своих потребностей в квалифицированных кадрах, степень и тип их вовлеченности в ГЧП варьирует в зависимости от формы собственности предприятия (рис. 3). Государственные предприятия с большей вероятностью будут вовлечены в обучение преподавательского состава, обеспечение финансирования и/или предоставление оборудования. Такие виды взаимодействия относятся к ГЧП общего типа. Совместные предприятия более осторожно относятся к выбору форм сотрудничества. Они предпочитают такие типы партнерств, где они могут контролировать качество обучения и получать выгоду в виде совместного подбора кадров, участия в разработке учебных планов и гарантий занятости для выпускников. Частные фирмы меньше всего готовы инвестировать в обучение преподавателей и оценку успеваемости студентов, поскольку это требует от них значительных затрат.

\section{2. Посредники и координация ГЧП}

2.1. Посредники и проблема коллективных действий

Как было показано в предыдущем разделе, правительства ряда китайских провинций смогли привлечь предприятия к участию в различных формах ГЧП с местными учреждениями СПО. Основываясь на нашем качественном анализе, мы полагаем, что успешное государственно-частное партнерство в сфере СПО само является скорее не решением проблемы коллективных действий, а результатом координации на рынке профессионального образования. Как сотрудничество между фирмами, так и сотрудничество между фирмами и учебными заведениями инициируется и поддерживается посредническими организациями. Они связывают фирмы и организации работодателей, учреждения общего и профессионального образования, органы власти, а иногда и другие организации (профсоюзы, НПО, аналитические центры и т.д.), чтобы привести деятельность образовательных учреждений в соответствие с потребностями работодателей (Remington, 2017).

Посредник может рассматриваться как институциональное решение проблем коллективных действий, в частности проблемы соблюдения обязательств со стороны партнеров (Remington, 2017). С этой целью они кон- 
Финансовая помощь учащимся

Мастера-наставники

Обучение преподавателей

Стипендия и заработная плата

Разработка учебных планов

Инвестиции

Предоставление оборудования

Гарантированная занятость

Совместный подбор кадров

Оценка успеваемости

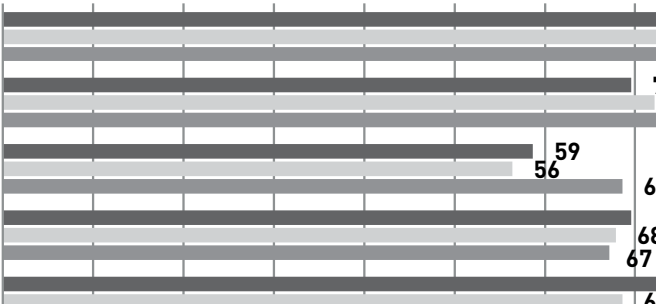

76

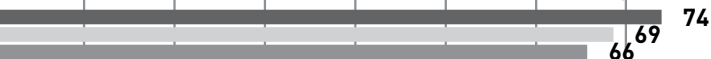

74

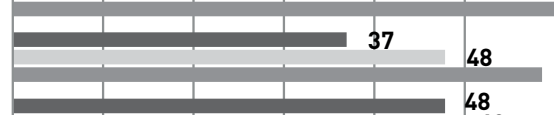

59

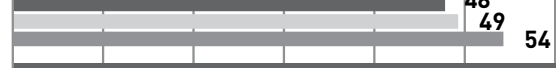

72
74

$68^{70}$
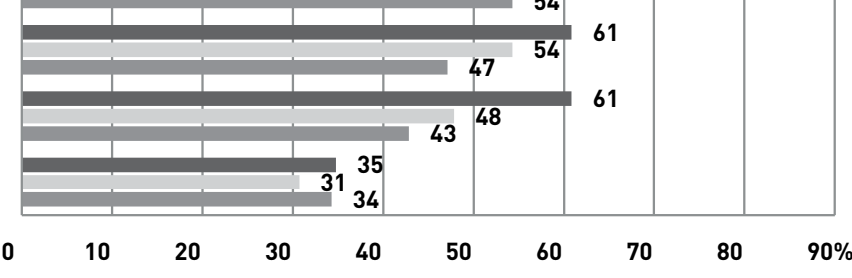

- Совместные предприятия

- Частные предприятия

п Государственные предприятия

Pис. 3

Уиастие в различнъх типах ГЧП в зависимости от формы собственности предприятия

тролируют деятельность каждого из партнеров, разрабатывая образовательные стандарты и квалификации, участвуя в согласовании учебных планов и проведении экзаменов, а также требуя соблюдения правил и договоренностей. Посредники могут укреплять партнерские отношения путем согласования различных интересов и содействия обмену информацией. Тем самым они способствуют расширению сотрудничества между фирмами, а также между фирмами и учебными заведениями.

\section{2. Координация внутри ГЧП} через посредников

Разные регионы Китая разработали различные формы посредничества для содействия сотрудничеству в сфере СПО. Некоторые из них являются государственными (публичное право), другие - частными (коммерческие или некоммерческие), третьи сочетают государственный и частный статус. В зависимости от степени сотрудничества между фирмами и сотрудничества между фирмами и образова- тельными учреждениями мы можем выделить четыре типа (модели) координации в рамках ГЧП (рис. 4): слабой связи; под руководством фирм; под руководством органов власти и совместной координации. Каждая модель отличается с точки зрения характера посредника и участников, типов сотрудничества в области обучения, распределения затрат, места приобретения навыков и их типов ${ }^{5}$.

\begin{tabular}{|c|c|c|c|}
\hline \multirow{3}{*}{$\begin{array}{r}\text { Уровень } \\
\text { взаимодействия } \\
\text { между фирмами } \\
\text { Низкий }\end{array}$} & \multicolumn{2}{|c|}{$\begin{array}{l}\text { Модель } \\
\text { под руководством }\end{array}$} & $\begin{array}{l}\text { Модель } \\
\text { совместной } \\
\text { координации }\end{array}$ \\
\hline & $\begin{array}{l}\text { Модель } \\
\text { слабой } \\
\text { связи }\end{array}$ & & $\begin{array}{l}\text { Модель } \\
\text { под руководством } \\
\text { органов власти }\end{array}$ \\
\hline & Низкий & \multicolumn{2}{|c|}{$\begin{array}{l}\text { взаимодействия } \\
\text { между фирмами } \\
\text { и учреждениями Спо }\end{array}$} \\
\hline
\end{tabular}

Рис. 4

Модели координачии внутри ГЧП

\footnotetext{
5 В модели слабой связи мы наблюдаем множество примеров двустороннего сотрудничества между отдельными учебными заведениями и фирмами, но при этом уровень сотрудничества остается низким. Эта модель не имеет очевидной посреднической организации, и поэтому мы ее далее не рассматриваем.
} 
Модель под руководством органов власти. В модели под руководством органов власти уровень сотрудничества между учреждениями СПО и фирмами является высоким, а между компаниями - низким. Местные органы власти часто назначают или создают организацию, которая выступает в качестве посредника. Эта модель распространена в регионах с высокой долей производственных отраслей, где концентрация промышленности приводит к высокому спросу на конкретные отраслевые навыки. Органы власти являются основными инвесторами в подготовку кадров на базе учреждений СПО, которые обеспечивают будущих работников необходимыми навыками. Кроме того, органы власти инвестируют в местные учебные базы и межфирменные учебные центры.

В качестве примера важной роли посредника в координации внутри ГЧП можно привести промышленный парк Сучжоу (SIP), расположенный в провинции Цзянсу. Для обеспечения подготовки кадров руководство SIP спонсирует агентство SIP Human Resource Department (SIPHRD). SIPHRD имеет квазиобщественный и квазичастный статус. SIPHRD предоставляет субсидии на подбор кадров для компаний, оказывает услуги для безработных, проводит обучение для работников-мигрантов, управляет кадровыми архивами для фирм и осуществляет подбор персонала для промышленного парка Сучжоу. Агентство также работает как коммерческое предприятие и заключает контракты с фирмами для найма сотрудников, сбора и публикации информации о местном рынке труда.

Что еще более важно, SIPHRD развивает стратегическое партнерство между фирмами и учреждениями СПО, в частности с Институтом технологий профессионального образования (IVT), для обучения работников специфическим для отрасли или конкретной фирмы навыкам. Чтобы программа обучения IVT соответствовала отраслевым стандартам, посредник участвует в разработке учебных программ и является членом Совета IVT. Oн также сотрудничает с IVT в создании межфирменных учебных центров для местных малых и средних предприятий (МСП). Таким образом, посредническая организация корректирует процесс обучения через межфирменные учебные программы для МСП или через IVT, чтобы обеспечивать подготовку квалифицированных кадров для крупных компаний, а также согласует потребности компаний разных размеров и разных отраслей промышленности.

Модель под руководством фирм. Модель под руководством фирм подразумевает высокий уровень сотрудничества между фирмами и относительно низкий - между компаниями и учреждениями СПО. В этой модели роль посредника играют отраслевые ассоциации. В промышленных агломерациях МСП и образовательные учреждения являются важными партнерами в сфере подготовки кадров. Фирмы и органы власти разделяют расходы на учебные программы, в том числе обучение на базе учреждения СПО, интенсивное обучение на рабочем месте и даже дуальное образование на предприятиях.

Например, отраслевые ассоциации стали ключевыми посредниками в авиационной промышленности в Чжучжоу, провинция Хунань. Созданный в 2013 г. Инновационный центр совместных разработок по аэронавтике и развитию технологий (Collaborative Innovation Center for Aeronautic Education and Technology Development) является отраслевой ассоциацией с 84 участниками, среди которых - специализированные профессиональные колледжи и университеты, предприятия авиационных технологий, научно-исследовательские институты, сервисные компании и государственные учреждения. Этот центр обеспечивает отраслевые стандарты обучения и способствует сотрудничеству между фирмами. В частности, в его функции входит контроль стандартов профессиональной подготовки и аттестации кадров, разработка учебных планов и согласование программ профессионального обучения с потребностями отрасли. Под наблюдением этого посредника компании авиационной промышленности могут сотрудничать друг с другом и на контрактной основе участвовать в обра- 
зовательном процессе, дуальном обучении, проводить оценку компетентности своих сотрудников. В данном случае учреждения СПО не столько обеспечивают потребности в квалифицированных работниках конкретных фирм, сколько помогают формировать навыки для отрасли в целом. При этом двусторонние связи между колледжами и фирмами остаются скорее слабыми

Бизнес-ассоциация также может стать катализатором на рынке СПО. С начала 1990-х годов некоторые немецкие предприятия перевели свои производства в город Тайцан в провинции Цзянсу. В Демонстрационной зоне сотрудничества МСП Китая и Германии немецкие бизнес-ассоциации договорились с Профессионально-техническим училищем Тайцан о создании межфирменного учебного центра по программе дуального образования. При поддержке местной деловой ассоциации и Торгово-промышленной палаты Германии (AHK-Shanghai) совместно с Kern-Libers CoLtd в 2001 г. был создан Центр профессиональной подготовки работников Тайцан. В Тайцане посредник смог убедить местные немецкие предприятия не заниматься переманиванием сотрудников и осуществить совместные инвестиции в подготовку кадров. В данном случае колледжи сотрудничают с фирмами-партнерами через межфирменные учебные центры, вместо того чтобы напрямую взаимодействовать с фирмами.

В качестве посредника ТПП Германии также поощряла создание ведущими фирмами собственных программ дуального образования с местными образовательными учреждениями. Профессиональнотехническое училище Тайцана сотрудничало с Schlaeffler Greater China для создания Учебного центра Schaeffler в 2005 г. и с Häring China - для создания Академии Häring в 2013 г. В 2015 г. Технологический институт Сучжоу, Университет Тунцзи и Schlaeffler Greater China совместно создали двойной бакалавриат при поддержке бизнес-ассоциации Германии и AHK-Shanghai. В этом случае ведущие фирмы работали с консорциумом учреждений СПО, вместо того чтобы созда- вать двустороннее партнерство с каждым образовательным учреждением отдельно.

Модель совместного управления. Модель совместного управления применяется, когда уровень сотрудничества между фирмами и между фирмами и учреждениями СПО является одинаково высоким. Государственные учреждения и отраслевые ассоциации объединяют свои усилия для координации местной системы подготовки кадров. Крупные частные фирмы и органы власти являются основными инвесторами на рынке профессионального обучения. Профессиональные колледжи, исследовательские университеты, отраслевые организации и МСП также участвуют в подготовке кадров. Обучение может проходить по программам дуального образования или обучения на базе учреждений СПО. Эта модель обеспечивает получение как общих навыков, так и навыков, необходимых для конкретной отрасли.

Модель совместного управления можно наблюдать на примере производства санитарно-гигиенических изделий, обуви и тканей в городе Цзиньцзян провинции Фуцзянь. При поддержке Бюро науки и техники и Бюро образования Цзиньцзяна Hengan International Group в кооперации с бизнес-ассоциацией санитарно-гигиенических изделий Фуцзяна и Технологическим институтом Цюаньчжоу создали совместную программу по подготовке специалистов для производства и технического обслуживания санитарного оборудования: 40 компаний бизнес-ассоциации вошли в совет этого специализированного учебного заведения. Бюро образования взяло на себя ответственность за соблюдение правил обучения и дало гарантии, что профессиональное образование соответствует отраслевым стандартам, в то время как деловая ассоциация согласовала интересы разных компаний и консолидировала их потребности в кадрах.

\section{3. Заключение}

Государственно-частное партнерство в области профессионального образования является новым явлением в Китае. В данной работе мы показали, что посреднические организации в сфере СПО имеют ключевое 
значение для решения проблемы коллективных действий на рынке СПО. Эти посредники координируют деятельность основных игроков, обеспечивают выполнение ими обязательств и создают доверие к мерам поощрения и взыскания, что делает возможным партнерство в области подготовки кадров. Наш анализ показывает, что такое посредничество может принимать различные формы: отраслевая ассоциация может способствовать сотрудничеству между фирмами в сфере СПО, квазигосударственные агентства могут обеспечивать соответствие спроса и предложения кадров, а государственные органы и бизнес-ассоциации могут разделять ответственность за координацию процесса обучения.

Однако в Китае эти перспективные модели координации ГЧП являются скорее исключением, чем правилом. Они часто включают определенные отрасли промышленности (например, отрасль с естественной монополией или высоким уровнем агломерации), типы компаний (например, немецкие МСП или крупные транснациональные корпорации) и регионы (например, богатые промышленные зоны). Их сложно скопировать без принципиальной корректировки системы СПО в Китае на основе институционализации сотрудничества между учебными заведениями, фирмами и правительством.

Вместе с тем есть много иных возможностей для стимулирования партнерства в сфере СПО. Прежде всего сюда относится стимулирование роста числа посреднических организаций на рынке профессионального образования. По мере того как местные правительства постепенно передают часть своих социальных и экономических функций гражданскому обществу, государственные, частные или квазигосударственные / квазичастные посреднические организации в сфере СПО могут способствовать установлению равновесия между спросом и предложением кадров. Создание учреждений СПО с государственным и частным участием также может стать успешной практикой. Как показывает опыт Цзиньцзяна, местные ведущие компании могут инвестировать в подобные учреждения СПО. При этом крупные фирмы могут обеспечить формирование необходимых навыков для всей отрасли и получать должным образом подготовленных сотрудников при сравнительно небольших затратах.

В настоящее время в Китае все популярнее становится еще один вариант ГЧП. Как отмечалось выше, центральное и региональное правительства Китая заинтересованы в привлечении на рынок СПО через механизмы ГЧП социальных партнеров, не являющихся работодателями. Эта форма позволяет частным и государственным инвесторам финансировать СПО с учетом потребностей конкретных предприятий. В рамках таких ГЧП социальные партнеры могут предоставлять платные образовательные услуги, заниматься строительством и управлением базовыми объектами или даже полностью взять на себя управление образовательным учреждением (Han, 2016). В ближайшее время представляется важным измерить и оценить влияние и эффективность подобных новых механизмов ГЧП в сфере СПО.

\section{ЛИТЕРАТУРА}

Acemoglu D., Pischke J.S. (1998). Why Do Firms Train? Theory and Evidence // Quarterly Journal of Economics. Vol. 113(1). P. 79-119.

Busemeyer M.R., Trampusch C. (2012). The Comparative Policical Economy of Collective Skill Formation. In: Busemeyer M.R., Tramsch C. (eds) "The political economy of collective skill formation”. London: Oxford University Press.

Han F. (2016). Promoting Government-Social Partner Collaboration in the Constructon of Modern Vocational Education System // Reviews of Economic Research. Vol. 61. P. 3-17.

IBM (2016). Pursuit of Relevance In: “IBM Institute of Business Values”. [Электронный pecypc] Режим доступа: https://www01.ibm.com/common/ssi/cgi-bin/ ssialias? subtype $=\mathrm{XB} \&$ infotype $=\mathrm{PM} \& \mathrm{chtm}$ lfid $=$ GBE03676USEN\&attachment $=$ GBE03676USEN.PDF, свободный. Загл. с экрана. Яз. анг. (дата обращения: август 2017 г.). 
IBM (2017). Facing the Perfect Storm: Global Skill Study. In: "IBM Institute of Business Values”. [Электронный ресурс] Режим доступа:https://www-01.ibm.com/common/ssi/cgi-bin/ssialias?htmlfid=GBE03788USEN\&, свободный. Загл. с экрана. Яз. анг. (дата обращения: август 2017 г.).

National Statistics Bureau (2016). 2015 Annual Monitoring Report on Chinese Migrant Workers. National Statistics Bureau. [Электронный ресурс] Режим доступа: http://www.stats.gov.cn/tjsj/ zxfb/201604/t20160428_1349713.html, свободный. Загл. с экрана. Яз. рус. (дата обращения: август 2017 г.).

Remington T.F. (2017). Thoughts on Intermediary Organizations in VET / / Personal communications. August 4.

Wang X. (2014). Social Construction of Skill Formation: Sociological Analysis of Transformation of Apprenticeship in China. Beijing: Social Science Archive Press.

Yang P., Wang X. (2017). China Manufacture 2025 and Skill Shortage Governance. Working paper series of Social Science Research Center. Beijing: Peking University.

Поступила в редакчию 9 июля 2017 года

REFERENCES (with English translation or transliteration)

Acemoglu D., Pischke J.S. (1998). Why Do Firms Train? Theory and Evidence. Quarterly Journal of Economics, 113(1), 79-119.

Busemeyer M.R., Trampusch C. (2012). The Comparative Policical Economy of Collective Skill Formation. In: Busemeyer M.R.,
Tramsch C. (eds). "The Political Economy of Collective Skill Formation”. London: Oxford University Press.

Han F. (2016). Promoting Government-Social Partner Collaboration in the Construction of Modern Vocational Education System. Reviews of Economic Research, 61, 3-17.

IBM (2016). Pursuit of Relevance In: “IBM Institute of Business Values". Available at: https:// www-01.ibm.com/common/ssi/cgi-bin/ ssialias?subtype $=\mathrm{XB} \&$ infotype $=\mathrm{PM} \&$ chtmlfid $=$ GBE03676 USEN\&attachment $=\mathrm{G}$ BE03676USEN.PDF (accessed: September 2017).

IBM (2017). Facing the Perfect Storm: Global Skill Study. In: "IBM Institute of Business Values". Available at: https://www-01.ibm.com/ common/ssi / cgi-bin/ssialias?htmlfid=GBE03788USEN\& (accessed: September 2017).

National Statistics Bureau (2016). 2015 Annual Monitoring Report on Chinese Migrant Workers. National Statistics Bureau. Available at: http://www.stats.gov.cn/tjsj/ zxfb/201604/t20160428_1349713.html (accessed: September 2017).

Remington T.F. (2017). Thoughts on Intermediary organizations in VET. Personal Communications, August 4.

Wang X. (2014). Social Construction of Skill Formation: Sociological Analysis of Transformation of Apprenticeship in China. Beijing: Social Science Archive Press

Yang P., Wang X. (2017). China Manufacture 2025 and Skill Shortage Governance. Working paper series of Social Science Research Center. Beijing: Peking University.

Received 9.10.2017

Po Yang

China Institute for Education Finance Research, Peking University, China

\section{Coordinating Public-Private Partnership in VET Sector: Evidence from China ${ }^{6}$}

Abstract. Chinese government encourages public-private-partnership (PPP) programs in vocational education (VET) sector in order to solve the collective action dilemma in training market.

\footnotetext{
${ }^{6}$ Po Yang thanks for financial support the China Social Science Foundation.
} 
The article reviews background and policy framework for PPP reform and its current development. Descriptive analysis based on 257 firm-college pairs and 1,679 specific collaboration practices between 171 vocational colleges and 257 industry partners show the most common forms of collaboration at provincial level include master instructors assigned by firms, faculty training, stipends and wages for students, and student aid. Moreover, there is a high degree of variation in terms of popularity of each practice among firms. Firm's choice of collaboration model depends on its ownership type. This paper further illustrates how intermediary organizations can facilitate inter-firm collaboration and schoolfirm cooperation under three PPP coordination models, including firm-led, government-led, and jointled model, based on analyses of multiple case studies in various Chinese regions. The paper concludes with a summary of findings and suggestions for future PPP coordination.

Keywords: public-private-partnership, China, intermediary organizations.

JEL Classification: D22, I28, I25, J24.

И. Маркес II

Национальный исследовательский университет «Высшая школа әкономики»,

факультет социальных наук, департамент политической науки, Москва

Профессиональное образование и механизмы государственно-частных партнерств

\section{в российских регионах ${ }^{1}$}

Аннотация. Исследования по проблемам экономического развития показывают, что рост производительности является важным фактором для перехода в категорию стран с высокими доходами. Профессиональное образование рассматривается как одно из средств достижения данной цели. Однако для этого необходимо соответствие между содержанием образовательных программ и спросом на квалификации со стороны предприятий. Усилия федеральных и региональных властей в России, направленные на пощрение государственно-частного партнерства (ГЧП) между предприятиями и учреждениями профессионального образования, - одно из средств обеспечения такого соответствия. Однако существует много различий между регионами в формах ГЧП и их внедрении. Данная статья описывает современные формы профессионального образования в России, используя оригинальные базы данных по ГЧП в регионах России, и пытается объяснить причины региональных различий в масштабах внедрения ГЧП в сфере профессионального образования.

Ключевые слова: среднее профессиональное образование (СПО), дуальное образование, практикоориентированное профессиональне обучение, государственно-частное партнерство, Россия.

Классификация JEL: D22, I28, I25, J24.

Исследователи ловушки среднего дохода отмечают, что главным препятствием для дальнейшего развития стран, достигших среднего уровня доходов, становится замедление роста производительности труда (Doner, Schneider, 2016). Такие страны оказываются «неспособны конкурировать в әкспорте промышленных товаров со странами с низким уровнем дохода и заработной платы и неспособны конкурировать с передовыми әкономиками в инновациях, требующих высокой квалификации...» (Kharas,
Kohli, 2011, р. 282). В России разрыв между квалификациями, которые нужны работодателям, и теми навыками, которыми обладают выпускники учебных заведений, представляется весьма глубоким. Этот разрыв может служить объяснением медленного роста әкономики в последние годы. Опросы бизнес-сообщества регулярно показывают, что более $60 \%$ российских фирм в числе наиболее острых проблем называют нехватку квалифицированных кадров (ОПОРА, 2012; РСПП, 2014).

1 Статья основана на результатах исследований, проведенных НИУ ВШЭ в рамках гранта Российского научного фонда (№ 16-18-10425) «Частно-государственное партнерство в среднем профессиональном образовании: на примере фирм в России и Китае». 